\title{
The Relationship Between Nurse Attitude and Students Self-Efficacy in Nursing Students Perceptive
}

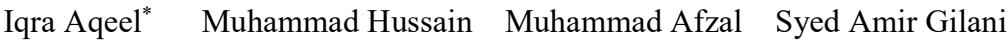 \\ Lahore School of Nursing, The University of Lahore
}

\begin{abstract}
Background: Clinical education is the methods by which nursing students are offered chances to apply the theories and learning of nursing, and work on nursing abilities that are basic to practice as a proficient staff nurse. For the competent clinical self efficacy, a caring relationship is necessary and essential for student learning in clinical setting. According to a study the clinical learning environment and supervision impact on clinical competency of nursing students. There is significant impact of supervisory relationship on clinical experience of students. The relationship between clinical faculty and nurse teacher also has impact in clinical self efficacy of the nursing student.Method: a descriptive co relational study design used in this study. The study conducted in The University of Lahore on 117 students of Nursing. The sample size calculated through Solvens formula. Clinical learning environment supervision and Nurse Teacher evaluation scale (CLES+T) and nursing clinical self efficacy scale (NCSES) questionnaire used in study. Results: there is positive correlation between clinical learning environment and self efficacy of students. The overall co relational value is $r=.336, p=.000$ at the level of 0.01 .Conclusion: It is concluded that the attitude of clinical staff has great impact on student clinical self efficacy. The creation a good clinical environment the clinical self efficacy of the student can be enhanced
\end{abstract}

Keywords: Relationship, Attitude, Clinical Self Efficacy, Nursing students, Perception

DOI: $10.7176 / \mathrm{JHMN} / 62-02$

Publication date:May $31^{\text {st }} 2019$

\section{Introduction}

Background: Clinical education is the methods by which nursing students are offered chances to apply the theories and learning of nursing, and work on nursing abilities that are basic to practice as a proficient staff nurse. For the competent clinical self efficacy, a caring relationship is necessary and essential for student learning in clinical setting.

The clinical learning environment develops competent skillful Nurses. It is suggested that to apply pedagogical competent atmosphere to students in clinical area of hospital(Pitkänen et al., 2018). The nursing students need chances to study more accurate syllabus in order to facilitate secure and efficient practice. One system to encourage such learning is the formation of learning situations. A loss of concentration on the learning situations in nursing has brought about inadequate information of the aspects of the learning situations. Nursing teachers need to have broad and practical information of the definition and attributes of the learning situations as to empower their students to accomplish good learning results(Shahsavari, Zare, Parsa-Yekta, Griffiths, \& Vaismoradi, 2018). The deficiency of nurses is one of the big dangers to the quality of care and patient security. There is necessary to give individual nursing care. The content of the work of Nurses in clinical setting can be make effective work place for competent staff Nurse to secure the patients. In this manner, it is significance for directors to include the experts in the advancement of clinical care, just as enabling experts to impact higher-level 
authoritative changes to guarantee quality in care and patient security(Persson \& Carlson, 2019). Good associations among students and supervisor have great impact on student learning. If students become part of team in clinical setting in the supervision of nurse supervisor make student confident have positive impact on student learning. One component that causes effective clinical learning among nursing students is great relational associations with Nursing supervisor and feeling some part of the group. In comparison, disappointment or negative practice were seen when the staff Nurse and Nursing supervisor did not have any concern for learning the nursing student(Ahmad \& Anwar, 2018). In the clinical setting there are different work giving to students in there clinical practice to enhance their knowledge which provide them conceptual framework to apply in different practices. Relationship among theory and practice in the practice are fundamental in their preparation as future nurses and in this manner in the development of professional character. In any case, clinical placement are the main component, as they give an uncommon chance to experience proficient reality and to most likely balance it with that transmitted in other educating settings or on the other hand progressively hypothetical systems. Additionally, clinical placement permits students to pick the nursing model with which they generally recognize. In this sense, the clinical placement guide is a basic figure the individual in question transmits components of professionals identification, accordingly helping students to build their way of life as future Nurse(Marañón \& Pera, 2015). The co-operation among students, nurse supervisor and clinical setting is most complicated and effective supervisory relationship in clinical practice. The nurse student co-operation method can make a remarkable change in nursing education practice. The nurse student co-operation is significant in the clinical practice for nursing education(StrandellLaine, 2019). The supervisory connection among students and mentor also, Nursing Teacher was observed to be a significant variable with regards to this study. The joint effort between mentor, Nursing Teacher, and nursing staff is seen decidedly, and is valuable in impacting positive clinical learning. There is a requirement for students fulfillment and view of a positive clinical practice to be viewed as depending on an organized path(Dimitriadou, Papastavrou, Efstathiou, \& Theodorou, 2015). In the admitted patients psychotherapy is one of the coping strategies for the distress. From the systematically reassurance of patient can cope from distress and patient can meet to positive coping style(Shen et al., 2018). Clinical practices output will assist the students with gaining information and self-assurance about their professional abilities. Additionally, in view of their dimension of selfefficacy, they can approach their informational needs, create procedures for clinical learning, and assess their very own learning(Mohamadirizi, Kohan, Shafei, \& Mohamadirizi, 2015). IM injection, insulin infusions, sterile dressing changes, and transfusions are processes regularly in clinical abilities labs. Students are frequently enhance the practice of these skills in the clinical setting also, and have many chances to do in future also. The students have chance to practice these skills in there clinical setting but, sometime may not be totally reasonable with regards to performing further developed skills, for example, Foley or NG addition. While clinical educators may enhance students to put these tube or practice further developed abilities, students may not feel easy install these invasive device in a real patient who will react to the procedure(Wilson \& Byers, 2017).

\section{PROBLEM STATEMENT}

In clinical setting the students is not getting adequate help and contact in clinical setting because the allocation of students is not appropriate and staff nurses are not adequate to give proper attention. In clinical area staff nurse attitude among the student effects on the student clinical competences. If the staff nurses attitude toward student 
is co operative, collaborative, and supporting the student learning will be improved and self efficacy of students will be enhance. Clinical practice happens in a complicated social setting with collective powers and is an imperative part of nursing instruction. It is really important to get it that the clinical atmosphere can positively affect student learning and can influence performance, and development. The idea of the learning atmosphere likewise has the significance of shared trust, relation and human properties. Current issues with clinical nursing training is that Students are not being to seek closely enough by the clinical educator or staff nurse, clinical instructors and staff work without respect to each other to help students.

\section{SIGNIFICANCE OF THE STUDY}

The significance of the study is that it is important for the student and staff Nurses positive attitude and relationship with each other to gain the clinical competence and to improve the self efficacy of student nurses. The present study will give the data to the clinical educators or teachers that which clinical training practices they should use in the clinical setting with students which will increase their clinical learning, attitude and practice. After the research, author will meet the significance of student and clinical instructor relationship to the more superior organization, this research will add the information to the clinical instructor of The university of Lahore by recommending that enhancement of the clinical instructing attitude adds to an increasingly positive result of the clinical experience by nursing students. The consequences of current research will also accommodate for the nursing students to accomplish their objectives in the clinical setting and it will improve the care of patients. After this study, information will be given to higher authorities who will be helpful to complete their study gapes through arranging the workshops. This research will support to me as a Nurse to adopt these competent clinical educating practices in my future experience.

\section{AIM OF THE STUDY}

The aim of the research is to see the relationship among nurse attitude and students self-efficacy in nursing students perceptive.

\section{Literature review}

A study carried in University of Akron, USA. This study was carried out to assess the perceptions of students about staff Nurses and self efficacy of the students. The study showing that, there is $0.417(\mathrm{r}=0.417)$ correlation among perception of student Nurses about the staff Nurses attitude and self efficacy in clinical practice. The correlation is fully significant at $0.01(\mathrm{p}=0.01)$. The average mean score of perception is 3.69 and average means score of clinical self efficacy of student Nurses is 7.49. This study found that there is huge positive correlation between independent and dependent variable(Mueller, Naragon, \& Smith, 2016). A research was conduct in Institute of Nursing of Isfahan University of Medical Sciences Iran to assess the relationship within clinical self

efficacy and clinical competency. The result of the study showing there is significant correlation among both variables $(\mathrm{P}<0.05, \mathrm{r}=0.69)$. The average mean score were $34.00 \pm 1,09$ and $79.01 \pm 0.3$ respectively(Mohamadirizi et al., 2015). A study was conducted to see the relationship among the self efficacy and learning motivation. According to this study there was the significant difference among self efficacy and students nurses $(\mathrm{P}=0.159)$. there is significant co relation between overall scoring of self efficacy and learning motivation $(r=0.233 ; \mathrm{p}=$ 
0.000)(Zhang et al., 2015). A study conducted in Cyprus University of technology to assess the experience of students about hospital learning environment and clinical supervision. Results of this study is that the student is satisfied who visited most of the time to their mentor and supervisor $(\mathrm{F}=3.3, P=0.01)$. The frequency of the students who visited to their mentor and supervisor is given. $35.5 \%$ students meet with their mentor individually, $26 \%$ students meet two time during clinical practice, and $38.6 \%$ student meets their mentor once time in a week(Dimitriadou et al., 2015) In the university of Edwardsville, a study was conducted to see the impact of clinical faculty on student self efficacy. According to this study significant correlation found between interpersonal relationship between faculty and nursing students $(\mathrm{r}=.170, \mathrm{p}=.009)$. the clinical teacher recommended the technique to improve self efficacy of students supervision $(\mathrm{p}=.011)$, good communication $(\mathrm{p}=.0239)$, and point out the strong and weak point of students $(\mathrm{p}=.012)$ (Rowbotham \& Owen, 2015). A descriptive co relational study was conducted in Cairo University in Egypt to assess the impact of clinical nursing teacher attitude and perception of students nurse toward their attitude. There is significant relationship between independent and dependent variable at $\mathrm{p}>.0001$. the correlation between both variables is teaching ability $=0.39$, students competences $=0.37$, and interpersonal relationship $=0.22$. The total quality of clinical teacher and student was $6.69 \pm 1.95$ (Ismail, Aboushady, \& Eswi, 2016). A study was carried out to gain the perception of student nurses about their relationship between theory and clinical placement and its influence on their professional clinical skills. The student's perception is that the theory and clinical setting is influencing on their professional capabilities. There part of clinical mentor is very essential in student learning and to develop the clinical confidence(Marañón \& Pera, 2015).

\section{METHODOLOGY}

Study design: Descriptive co relational study design will be used.

Settings: Study will be conducted in school of nursing private University of Lahore.

Target population: The population consisted of senior Nursing students of private University of Lahore.

Inclusion Criteria: Inclusion criteria of study involve; English medium senior students of baccalaureate BSN nursing and baccalaureate Nursing (Post RN) students, those have interaction with clinical setting like $2^{\text {nd }} \& 4^{\text {th }}$ semester of baccalaureate Nursing (Post RN) and $3^{\text {rd }}, 5^{\text {th }}$, and $7^{\text {th }}$ semester of baccalaureate BSN nursing

Exclusion Criteria: Exclusion criteria of study involve; lack clinical experience, which affects their ability to report Attitudes of staff in clinical environments

Sample Size: The sample size will be calculated through Solvens formula

$$
\begin{aligned}
& n=N / 1+N(e) 2 \\
& n=166 / 1+166(0.005) 2 \\
& n=166 / 1+0.415 \\
& n=166 / 1.415 \\
& n=117
\end{aligned}
$$

Sample techniques: Random sampling technique will be use in this study.

Instruments: Self-efficacy was measured with a 22-item Nursing Clinical Self-Efficacy Scale (NCSEC). The validity and reliability check by value of cronbachs Alpha (.0821) that showing instrument is reliable. 
Perceived staff attitudes were measured with CLES+T questionnaire. The learning Environment and the role of the staff nurse were measured on five sub-dimensions. The validity and reliability check by value of cronbachs Alpha (.0821) that showing instrument is reliable.

Data Collection Techniques: The data collection will be done by the use of two instruments 1: Nursing Clinical Self-Efficacy Scale (NCSEC) and CLES+T questionnaire.

Data Analysis: The data will be analysis through SPSS software stand for statically package for social sciences (SPSS). It's used for statically analysis of data and interpretation of data.

Variables : Independent Variables; Attitude of staff nurses toward students

Dependent variables; Self efficacy

\section{Results}

In the study total sample size is 117 both male and females. The aim of the research is to investigate the relationship within nurse attitude and student self efficacy in nursing student perceptive. The demographic of the participants describe below.

Table 1; demographic of participants /

\begin{tabular}{|c|c|c|c|}
\hline \multicolumn{2}{|c|}{ Characteristics } & \multirow{2}{*}{$\begin{array}{l}\text { Frequency } \\
5\end{array}$} & \multirow{2}{*}{$\begin{array}{l}\text { Percentage } \\
4.3\end{array}$} \\
\hline Gender & Male & & \\
\hline & Female & 112 & 95.7 \\
\hline \multirow[t]{2}{*}{ Status } & Married & 20 & 17.1 \\
\hline & Unmarried & 97 & 82.9 \\
\hline \multirow[t]{3}{*}{ Age } & $20-25$ & 84 & 71.8 \\
\hline & $26-30$ & 27 & 23.1 \\
\hline & $31-35$ & 6 & 5.1 \\
\hline \multirow[t]{4}{*}{ Year } & $1^{\text {st }}$ year & 9 & 7.7 \\
\hline & $2^{\text {nd }}$ year & 61 & 52.1 \\
\hline & $3^{\text {rd }}$ year & 35 & 29.9 \\
\hline & $4^{\text {th }}$ year & 12 & 10.3 \\
\hline \multirow[t]{4}{*}{ Discipline } & Diploma in Nursing & - & - \\
\hline & Bachelor in Nursing & 59 & 40.4 \\
\hline & Master in Nursing & - & - \\
\hline & BSN( Post RN ) & 58 & 49.6 \\
\hline \multirow[t]{4}{*}{ Experience } & $1-5$ & 91 & 77.8 \\
\hline & $6-10$ & 21 & 17.9 \\
\hline & $11-15$ & 1 & 1 \\
\hline & $16-20$ & 4 & 3.3 \\
\hline \multirow[t]{4}{*}{ CGPA } & $2-2.5$ & 10 & 8.5 \\
\hline & $2.6-3$ & 29 & 24.8 \\
\hline & $3.1-3.5$ & 60 & 51.3 \\
\hline & $3.6-4$ & 18 & 15.4 \\
\hline
\end{tabular}




\section{Normality of data}

Table 11

\begin{tabular}{llr}
\hline \multicolumn{2}{c}{ Estimated Distribution Parameters } \\
\hline \multirow{2}{*}{ Normal Distribution } & Location & CLES+T \\
& Scale & .20997
\end{tabular}

Table showing normal distribution in location value 3.9771 against .20997 scales

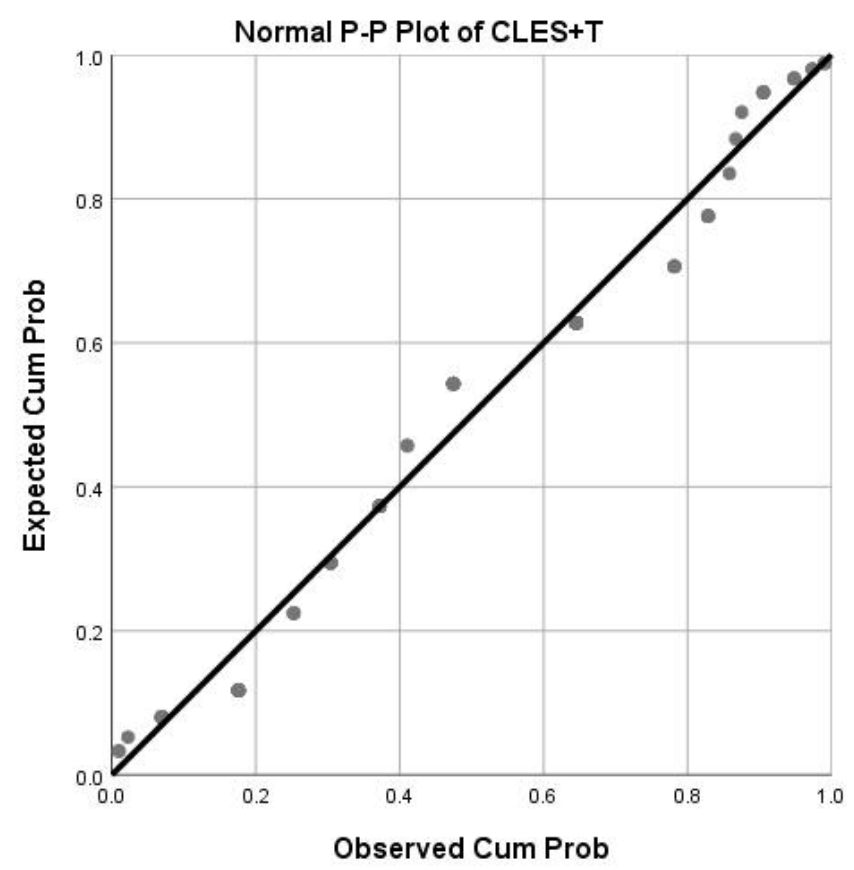

Figure 8 showing normal distribution

\section{Table 12}

\begin{tabular}{llr}
\hline & Estimated Distribution Parameters & \\
\hline & & NCSES \\
Normal Distribution & Location & 7.6406 \\
& Scale & .60726
\end{tabular}


Table 5 showing normal distribution in location value 7.6406 against .60726 scales.

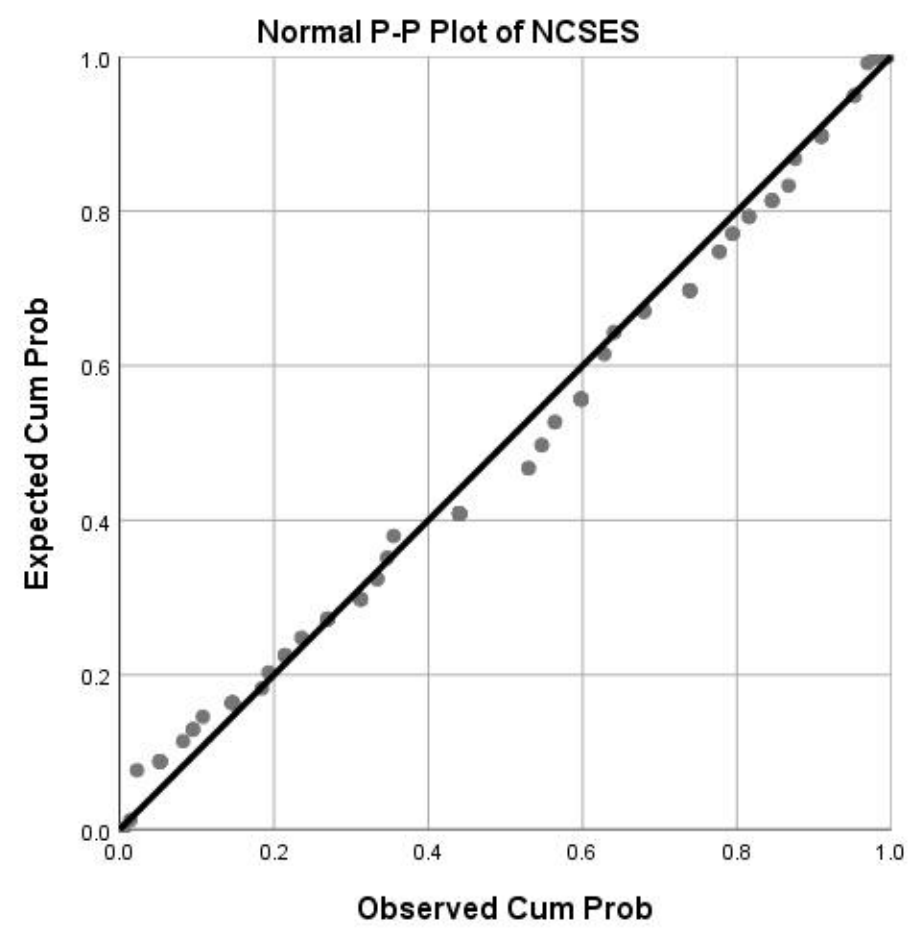

Figure 9showing normal distribution

The results showing that there is significant correlation within the learning environment pedagogical atmosphere and nursing clinical self efficacy $(r=.997, p=-0.000)$. There is significant correlation between Premises of nursing in ward and nursing clinical self efficacy $(r=.999, \mathrm{p}=-0.000)$. There is significant correlation between the supervisory relationship and nursing clinical self efficacy $(r=-.989, p=-0.000)$. There is significant correlation between role of the nursing teacher and nursing clinical self efficacy scale $(r=-.991, p=-0.000)$. There is significant correlation between relationship among mentor and nurse teacher of students with clinical self efficacy $(r=.989$, $\mathrm{p}=.000$ ). There is overall results of the study are there is significant correlation at the 0.05 level.

\section{Discussion}

Including all of participants in the study results shows the there is significant correlation $(r=.336, p=-0.000)$ between nursing students perception and self efficacy of students. This results shows that an student who reports a progressively positive perception of staff nurse towards that students, likewise tends to show a more elevated amount of self-adequacy of clinical expertise practices. These outcomes recommend that staff nurse behavior toward nursing students who are rehearsing in a clinical setting have positive or negative on self efficacy of nursing students. The social learning theory is supporting the study by theoretical framework.

According to a study the clinical learning environment and supervision impact on clinical competency of nursing students. There is significant impact of supervisory relationship on clinical experience of students (Pitkänen et al., 2018). In another study's results shows that premises of nursing greatly impact and correlate with student competences and enhance the delivery in quality of care. The collaboration between staff, nurse teacher and mentor also beneficial for the enhancement of positive learning environment (Dimitriadou et al., 2015). 
The clinical skill is greatest step in clinical professional learning which has impact from clinical learning environment, premises of nursing in ward, supervisory relationship, co operative relationship within hospital area instructor, association in mentor instructor on clinical self efficacy of the nursing students.

Table 18; correlation of CLES+T domains and NCSES

\begin{tabular}{|c|c|c|c|c|c|c|c|c|}
\hline \multicolumn{9}{|c|}{ Correlations } \\
\hline & & Domain 11 & main 2 & Domain3 & Domain 4 & Domain 5 & Domain 6 & NCSES \\
\hline \multirow[t]{3}{*}{ Domain 1} & Pearson Correlation & 1 & $.994^{* *}$ & $.977^{* *}$ & $.995^{* *}$ & $.986^{* *}$ & $.997^{* *}$ & $.583^{* *}$ \\
\hline & Sig. (2-tailed) & & .000 & .000 & .000 & .000 & .000 & .000 \\
\hline & $\mathrm{N}$ & 117 & 117 & 117 & 117 & 117 & 117 & 117 \\
\hline \multirow[t]{3}{*}{ Domain 2} & Pearson Correlation & $.994^{* *}$ & 1 & $.991^{* *}$ & $.990^{* *}$ & $.991^{* *}$ & $.999^{* *}$ & $.502^{* *}$ \\
\hline & Sig. (2-tailed) & .000 & & .000 & .000 & .000 & .000 & .000 \\
\hline & $\mathrm{N}$ & 117 & 117 & 117 & 117 & 117 & 117 & 117 \\
\hline \multirow[t]{3}{*}{ Domain 3} & Pearson Correlation & $.977^{* *}$ & $.991^{* *}$ & 1 & $.963^{* *}$ & $.969^{* *}$ & $.989^{* *}$ & $.435^{* *}$ \\
\hline & Sig. (2-tailed) & .000 & .000 & & .000 & .000 & .000 & .000 \\
\hline & $\mathrm{N}$ & 117 & 117 & 117 & 117 & 117 & 117 & 117 \\
\hline \multirow[t]{3}{*}{ Domain 4} & Pearson Correlation & $.995^{* *}$ & $.990^{* *}$ & $.963^{* *}$ & 1 & $.994^{* *}$ & $.991^{* *}$ & $.581^{* *}$ \\
\hline & Sig. (2-tailed) & .000 & .000 & .000 & & .000 & .000 & .000 \\
\hline & $\mathrm{N}$ & 117 & 117 & 117 & 117 & 117 & 117 & 117 \\
\hline \multirow[t]{3}{*}{ Domain 5} & Pearson Correlation & $.986^{* *}$ & $.991^{* *}$ & $.969^{* *}$ & $.994^{* *}$ & 1 & $.989^{* *}$ & $.500^{* *}$ \\
\hline & Sig. (2-tailed) & .000 & .000 & .000 & .000 & & .000 & .000 \\
\hline & $\mathrm{N}$ & 117 & 117 & 117 & 117 & 117 & 117 & 117 \\
\hline \multirow[t]{3}{*}{ Domain 6} & Pearson Correlation & $.997^{* *}$ & $.999^{* *}$ & $.989^{* *}$ & $.991^{* *}$ & $.989^{* *}$ & 1 & $.528^{* *}$ \\
\hline & Sig. (2-tailed) & .000 & .000 & .000 & .000 & .000 & & .000 \\
\hline & $\mathrm{N}$ & 117 & 117 & 117 & 117 & 117 & 117 & 117 \\
\hline \multirow[t]{3}{*}{ NCSES } & Pearson Correlation & $.583^{* *}$ & $.502^{* *}$ & $.435^{* *}$ & $.581^{* *}$ & $.500^{* *}$ & $.528^{* *}$ & 1 \\
\hline & Sig. (2-tailed) & .000 & .000 & .000 & .000 & .000 & .000 & \\
\hline & $\mathrm{N}$ & 117 & 117 & 117 & 117 & 117 & 117 & 117 \\
\hline
\end{tabular}

\section{Conclusion}

From this study it is concluded that, the nursing students experience in clinical setting has great part of their learning, enhancement of clinical self efficacy and to improve professional development. Clinical environment and clinical self efficacy has significant correlation. The relationship between clinical faculty and nurse teacher also has impact in clinical self efficacy of the nursing student. The attitude of clinical staff has great impact on student clinical self efficacy. The results show that with the creation a good clinical environment the clinical self efficacy of the student can be enhanced. Other studies is giving support to my study and proved that the results of this study are significant. 


\section{Limitation and recommendation}

The shortage of the time to take data and some negative behavior of the students to filling the questionnaire and only one institute for data collection is the limitation of my study therefore there is some negative correlation between variable.

The attitude of clinical staff should be co operative and collaborative with their students. There must be good relationship between clinical staff and nursing faculty. There should be an assessment tool from nursing faculty for the evaluation of student's clinical self efficacy.

\section{Acknowledgment}

Firstly a biggest thank Almighty ALLAH to give me the courage and guidelines in this research I am happy to show my obligations to Supervisor Sir Hussain faculty in Lahore School of Nursing The University of Lahore, who always listen to me and Give me guidance. I am also very thankful to Muhammad Afzal Principle Lahore School of Nursing, The University of Lahore for his guidance and opportunity

\section{DEDICATIONS}

The dedication of my all work goes to my FAMILY who support me especially to my elder sister MEHREEN AQEEL who support me in every step and encourage me for studies further. Also credit goes to my honorable principal MUHAMMAAFZAL and respected Teacher Sir HUSSAIN who always guide me in conducting research.

\section{REFERENCES}

Ahmad, N., \& Anwar, N. H. K. (2018). Nursing Students and Clinical Instructors' Perceptions of Clinical Learning Environments, Supervision, and Teaching (CLES-T). International Journal Of Care Scholars, 1(1), 10-13.

Dimitriadou, M., Papastavrou, E., Efstathiou, G., \& Theodorou, M. (2015). Baccalaureate nursing students' perceptions of learning and supervision in the clinical environment. Nursing \& health sciences, 17(2), 236242.

Ismail, L. M.-N., Aboushady, R. M.-N., \& Eswi, A. (2016). Clinical instructor's behavior: Nursing student's perception toward effective clinical instructor's characteristics. Journal of Nursing Education and Practice, $6(2), 96$.

Marañón, A. A., \& Pera, M. P. I. (2015). Theory and practice in the construction of professional identity in nursing students: A qualitative study. Nurse Education Today, 35(7), 859-863.

Mohamadirizi, S., Kohan, S., Shafei, F., \& Mohamadirizi, S. (2015). The relationship between clinical competence and clinical self-efficacy among nursing and Midwifery students. International Journal of Pediatrics, 3(6.2), 1117-1123.

Mueller, S. A., Naragon, R. M., \& Smith, R. R. (2016). The Relationship Between Nursing Students' Perceptions of Staff Nurses' Attitudes Towards Them and Self-Efficacy in Sophomore-and Senior-Level Nursing Students.

Pavlov, I., Watson, J., Skinner, B., \& Thorndike, E. Bandura-Social Learning Theory.

Persson, U., \& Carlson, E. (2019). Conceptions of professional work in contemporary health care-Perspectives 
from registered nurses in somatic care: A phenomenographic study. Journal of clinical nursing, 28(1-2), 201208.

Pitkänen, S., Kääriäinen, M., Oikarainen, A., Tuomikoski, A.-M., Elo, S., Ruotsalainen, H., . . Mikkonen, K. (2018). Healthcare students' evaluation of the clinical learning environment and supervision-a cross-sectional study. Nurse Education Today, 62, 143-149.

Rowbotham, M., \& Owen, R. M. (2015). The effect of clinical nursing instructors on student self-efficacy. Nurse education in practice, 15(6), 561-566.

Shahsavari, H., Zare, Z., Parsa-Yekta, Z., Griffiths, P., \& Vaismoradi, M. (2018). Learning Situations in Nursing Education: A Concept Analysis. Research and theory for nursing practice, 32(1), 23-45.

Shen, X., Zhu, X., Wu, Y., Zhou, Y., Yang, L., Wang, Y., . . Xiao, N. (2018). Effects of a psychological intervention programme on mental stress, coping style and immune function in percutaneous coronary intervention patients. PLOS ONE, 13(1).

Strandell-Laine, C. (2019). Nursing student-nurse teacher cooperation using mobile technology during the clinical practicum.

Wilson, M., \& Byers, T. (2017). Relationship Between Self-Efficacy and Work Experience in Baccalaureate Junior and Senior Level Nursing Students.

Zhang, Z.-J., Zhang, C.-L., Zhang, X.-G., Liu, X.-M., Zhang, H., Wang, J., \& Liu, S. (2015). Relationship between self-efficacy beliefs and achievement motivation in student nurses. Chinese Nursing Research, 2(2-3), 67-70. 